\title{
Chemical Comparison of Two Drying Methods of Mountain Cultivated Ginseng by UPLC-QTOF-MS/MS and Multivariate Statistical Analysis
}

\author{
Xin-fang $X u^{1}{ }^{1}$, Shu-ya $X u^{1}$, Ying Zhang ${ }^{1}$, Hui Zhang ${ }^{1}$, Meng-nan Liu ${ }^{1}$, Huan Liu ${ }^{1}$, Yan Gao ${ }^{1}$, \\ Xue Xue ${ }^{1}$, Hui Xiong ${ }^{1}$, Rui-chao Lin ${ }^{1,2}$ and Xiang-ri Li ${ }^{1,2, *}$ \\ 1 School of Chinese Materia Medica, Beijing University of Chinese Medicine, No. 6 \\ Wangjing zhonghuannan Road, Beijing 100102, China; xuxinfang007@163.com (X.-f.X.); \\ xushuya11@163.com (S.-y.X.); zhang0312ying@163.com (Y.Z.); zh19930503@sina.com (H.Z.); \\ 20160931810@bucm.edu.cn (M.-n.L.); 20150931937@bucm.edu.cn (H.L.); 20150931752@bucm.edu.cn (Y.G.); \\ sherry.xue@bucm.edu.cn (X.X.); xionghui@bucm.edu.cn (H.X.); linrch307@sina.com (R.-c.L.) \\ 2 Beijing Key Laboratory for Quality Evaluation of Chinese Materia Medica, Beijing University of \\ Chinese Medicine, No. 11 North Third Ring Road, Beijing 100029, China \\ * Correspondence: lixiangri@sina.com; Tel.: +86-10-8473-8616 \\ Academic Editor: Anusha Chaparala \\ Received: 14 April 2017; Accepted: 27 April 2017; Published: 30 April 2017
}

\begin{abstract}
In traditional Chinese medicine practice, drying method is an essential factor to influence the components of Chinese medicinal herbs. In this study, an ultra-performance liquid chromatography quadrupole time-of-flight tandem mass spectrometry (UPLC-QTOF-MS/MS)-based approach was used to compare the content of chemical compounds of mountain cultivated ginseng that had been natural air dried (LX-P) and vacuum freeze-dried (LX-L). Multivariate statistical analysis such as principal component analysis (PCA) and supervised orthogonal partial least squared discrimination analysis (OPLS-DA) were used to select the influential components of different samples. There were 41 ginsenosides unambiguously identified and tentatively assigned in both LX-L and LX-P. The results showed that the characteristic components in LX-P were ginsenoside $\mathrm{Rb} 1$, ginsenoside $\mathrm{Rc}$, ginsenoside $\mathrm{Rg} 6$, dendrolasin, and ginsenoside $\mathrm{Rb} 2$. The characteristic components in LX-L were malonyl-ginsenoside Re, malonyl-ginsenoside Rb1, malonyl-ginsenoside $\mathrm{Rc}$, malonyl-ginsenoside $\mathrm{Rb} 1$ isomer, malonyl-ginsenoside $\mathrm{Rb} 2$, malonyl-ginsenoside $\mathrm{Rb} 3$, malonyl-ginsenoside Rd isomer, gypenoside XVII, and notoginsenoside Fe. This is the first time that the differences between LX-L and LX-P have been observed systematically at the chemistry level. It was indicated that vacuum freeze-drying method can improve the content of malonyl-ginsensides in mountain cultivated ginseng.
\end{abstract}

Keywords: mountain cultivated ginseng (MCG); UPLC-QTOF-MS/MS; OPLS-DA; PCA; vacuum freeze-drying

\section{Introduction}

The root and rhizome of ginseng, Panax ginseng C.A. Meyer (Araliaceae), has been widely used as a traditional Chinese medicine and a functional food to prevent various diseases in the Orient [1]. Numerous research has shown that Panax ginseng possesses many pharmacological properties relating to the central nervous system [2], cardiovascular system [3], and aging process [4], which exhibits antioxidant [5], anticancer [6], and immunomodulatory effects [7]. The active components of ginseng are attributed to polysaccharides, ginsenosides, and volatile oil.

Mountain cultivated ginseng (MCG), which is grown in forests and mountains, can be considered to mimic mountain wild ginseng (MWG) [8]. Normally, MCG is harvested at the age of 10-20 years 
or more, and cultivated ginseng (CG) is often collected after 4-7 years [9]. Pharmacopoeia of the People's Republic of China also classified ginseng into CG and MCG groups [10]. Nevertheless, as a substitute of MWG, MCG is of better quality than CG. Pharmacological researchers also have revealed that MCG has greater anticancer activities than CG [11]. More significantly, MCG can keep the balance of the ecological environment. Therefore, MCG has great potential value in clinical applications and environmental conservation.

The drying process is an essential factor for the quality of ginseng products, which directly relates to the variety of chemical components. After obtaining MCG samples, the drying process is necessary to reduce moisture content and water activity, which can keep it in a good quality for a long period of time. Besides, high moisture content of ginseng enhances microbiological growth, as well as enzymatic and non-enzymatic reactions that can result in a rapid deterioration of the ginseng and thus a reduction in its possible medicinal and commercial value [12]. The traditional drying process is drying ginseng in the natural air or in the sun. With the development of science and technology, many drying methods and equipment have been developed, such as forced air drying [13], vacuum freeze-drying [14], microwave drying [15], vacuum microwave drying [16], and far-infrared drying [17]. Natural air drying is a traditional drying method that was considered convenient and without cost. In recent years, vacuum freeze-drying, widely used in food and medicine fields, started to be used more widely for the preservation of Chinese herbs. Vacuum freeze-drying is a drying process in which the solvent contained inside the products is removed from a frozen solution by sublimation [18,19]. MCG, after vacuum freeze-drying, can keep consistent with its fresh condition in shape and color and contains more natural active components, which is often called active ginseng. Significant changes in the color, texture, and odor are directly related to the chemical content of ginseng samples. So, the chemical profiling of MCG that has been vacuum freeze-dried (LX-L) and natural air dried (LX-P) are important for the proper usage of ginseng.

In the past few decades, many analytical technologies have been frequently applied to identify and differentiate ginseng products. The studies for identifying ginseng in different drying methods focused on the chemical components including ginsenosides [20], polysaccharides [21], reducing sugars [22], amino acids [23] and volatile oil [24], etc. Among this research, the components of ginseng products were very similar in category and content. These methods were merely used to determine the major ginsenosides using high performance liquid chromatography (HPLC) and ultra-performance liquid chromatography tandem mass spectrometry (UPLC-MS), and to focus on cultivated ginseng (CG). There is no research to date that has systematically analyzed the difference between mountain cultivated ginseng (MCG) subjected to vacuum freeze-drying and natural air drying through identifying their chemical components.

In our study, we developed a sample profiling strategy combining UPLC-QTOF-MS/MS and multivariate statistical analysis (MVA) as the analytical tools to analyze the chemical contents of LX-P and LX-L. This strategy has the advantages of ultra-performance liquid chromatography (UPLC) for high resolution, high sensitivity, and high-speed separation, as well as time-of-flight mass spectrometry (TOF) for exact mass measurement capability. Moreover, MVA, especially the principle component analysis (PCA) and orthogonal projections from latent structures discriminant analysis (OPLS-DA), has been used to identify the differences between the samples. This method allows us to understand the subtle differences between LX-P and LX-L. More significantly, it can find the different marker components and their chemical structures to help identify mountain cultivated ginseng products easily. This is the first time that the differences between LX-P and LX-L have been systematically observed from the level of chemistry components. 


\section{Results and Discussions}

\subsection{UPLC-MS Analysis}

As shown in previous articles, the ACQUITY BEH $C_{18}$ column has frequently been used to analyze ginsenosides from various ginseng products. Figure 1 shows the Based Peak Intensity (BPI) chromatograms obtained from the analysis of LX-L and LX-P in positive ion mode. The resultant peaks indicate that the components were complex in both MCG samples. There were 41 ginsenosides identified in LX-L and LX-P, including protopanaxatriol, panoxadiol, and their derivates. Among these ginsenosides, eight compounds were assigned by comparing them to standard ginsenosides, and 33 ginsenosides were identified by comparing their retention times and mass spectra with the reference compounds. The ginsenosides were further confirmed through ion fragmentation patterns. As illustrated in Table 1, ginsenosides were detected as protonated ions $[\mathrm{M}+\mathrm{H}]^{+}$, sodium adduct ions $[\mathrm{M}+\mathrm{Na}]^{+}$and/or ammonium adduct ions $\left[\mathrm{M}+\mathrm{NH}_{4}\right]^{+}$in the positive ion mode.

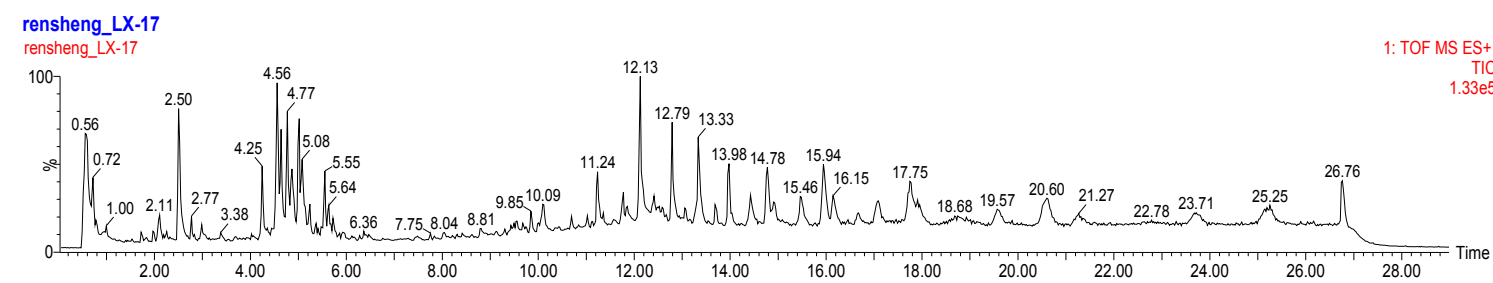

(A)

rensheng_LX-LD-14

rensheng_LX-LD-14

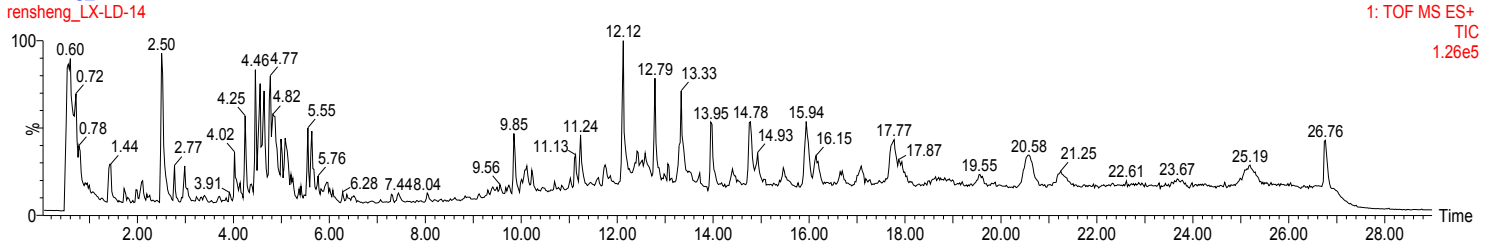

(B)

Figure 1. Representative based peak intensity (BPI) chromatograms of LX-P and LX-L samples. (A) Natural air dried ginseng (LX-P); (B) Vacuum freeze-dried ginseng (LX-L).

Table 1. Characterization of ginsenosides in LX-L and LX-L using UPLC-QTOF-MS/MS.

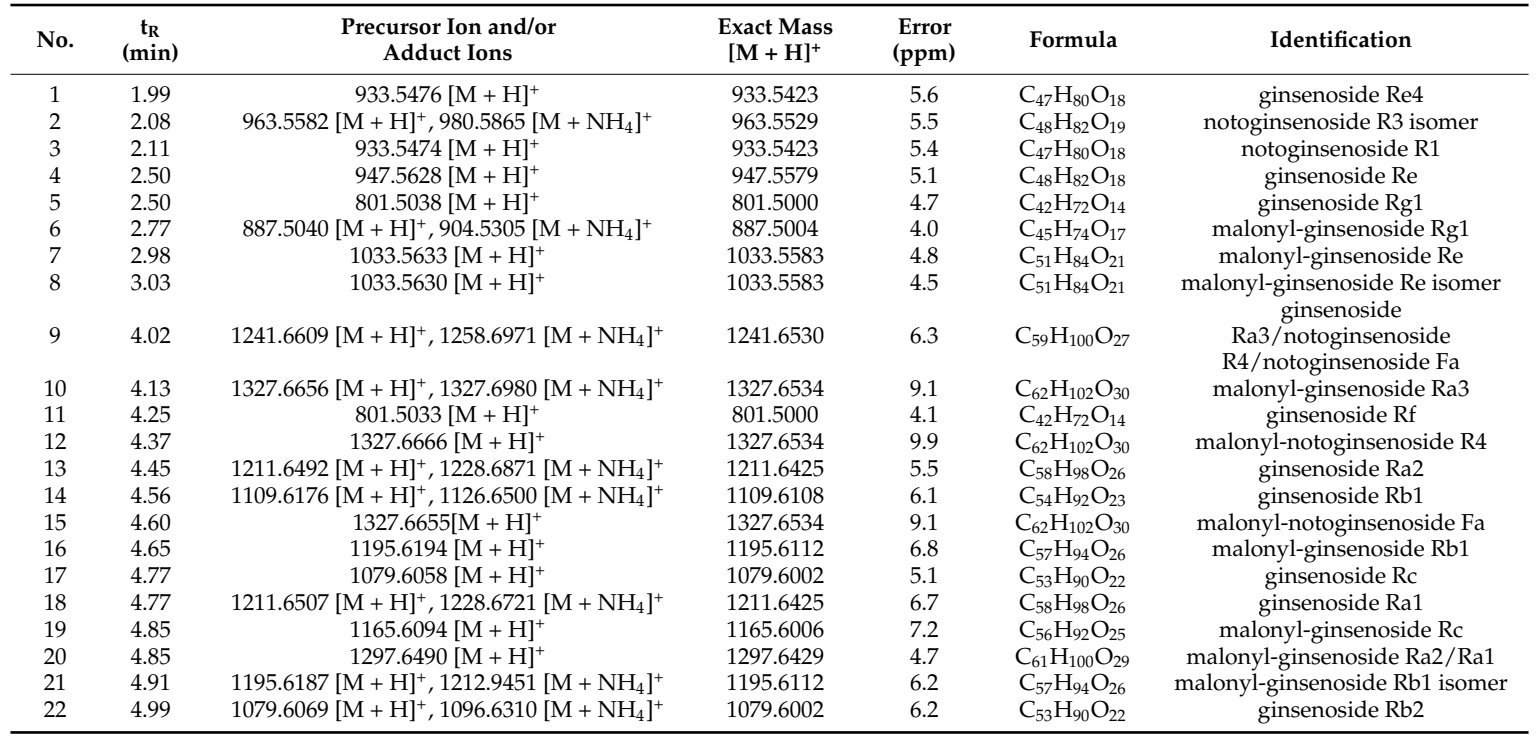


Table 1. Cont.

\begin{tabular}{|c|c|c|c|c|c|c|}
\hline No. & $\begin{array}{c}t_{R} \\
(\min )\end{array}$ & $\begin{array}{l}\text { Precursor Ion and/or } \\
\text { Adduct Ions }\end{array}$ & $\begin{array}{l}\text { Exact Mass } \\
{[\mathrm{M}+\mathrm{H}]^{+}}\end{array}$ & $\begin{array}{l}\text { Error } \\
(\mathrm{ppm})\end{array}$ & Formula & Identification \\
\hline 23 & 5.10 & $1165.6088[\mathrm{M}+\mathrm{H}]^{+}, 1182.641\left[\mathrm{M}+\mathrm{NH}_{4}\right]^{+}$ & 1165.6006 & 7.0 & $\mathrm{C}_{56} \mathrm{H}_{92} \mathrm{O}_{25}$ & malonyl-ginsenoside $\mathrm{Rb} 2$ \\
\hline 24 & 5.23 & $1151.6284[\mathrm{M}+\mathrm{H}]^{+}, 1168.6471\left[\mathrm{M}+\mathrm{NH}_{4}\right]^{+}$ & 1151.6213 & 6.1 & $\mathrm{C}_{56} \mathrm{H}_{94} \mathrm{O}_{24}$ & quinquenoside R1 \\
\hline 26 & 5.37 & $1165.6067[\mathrm{M}+\mathrm{H}]^{+}, 1182.641\left[\mathrm{M}+\mathrm{NH}_{4}\right]^{+}$ & 1165.6006 & 5.2 & $\mathrm{C}_{56} \mathrm{H}_{92} \mathrm{O}_{25}$ & malonyl-ginsenoside $\mathrm{Rb} 3$ \\
\hline 27 & 5.41 & $1165.6085[\mathrm{M}+\mathrm{H}]^{+}, 1182.641\left[\mathrm{M}+\mathrm{NH}_{4}\right]^{+}$ & 1165.6006 & 6.7 & $\mathrm{C}_{56} \mathrm{H}_{92} \mathrm{O}_{25}$ & malonyl-ginsenoside $\mathrm{Rb} 3$ isomer \\
\hline 28 & 5.55 & $947.5621[\mathrm{M}+\mathrm{H}]^{+}, 964.5913\left[\mathrm{M}+\mathrm{NH}_{4}\right]^{+}$ & 947.5579 & 4.4 & $\mathrm{C}_{48} \mathrm{H}_{82} \mathrm{O}_{18}$ & ginsenoside $\mathrm{Rd}$ \\
\hline 29 & 5.56 & $767.4960[\mathrm{M}+\mathrm{H}]^{+}$ & 767.4960 & 1.8 & $\mathrm{C}_{42} \mathrm{H}_{70} \mathrm{O}_{12}$ & ginsenoside $\operatorname{Rg} 6$ \\
\hline 32 & 5.92 & $1033.5653[\mathrm{M}+\mathrm{H}]^{+}, 1050.590\left[\mathrm{M}+\mathrm{NH}_{4}\right]^{+}$ & 1033.5583 & 6.7 & $\mathrm{C}_{51} \mathrm{H}_{84} \mathrm{O}_{21}$ & malonyl-ginsenoside Rd isomer \\
\hline 33 & 5.95 & $947.5623[\mathrm{M}+\mathrm{H}]^{+}$ & 947.5579 & 4.6 & $\mathrm{C}_{48} \mathrm{H}_{82} \mathrm{O}_{18}$ & gypenoside XVII \\
\hline 34 & 6.01 & $1121.6180[\mathrm{M}+\mathrm{H}]^{+}$ & 1121.6108 & 5.9 & $\mathrm{C}_{55} \mathrm{H}_{92} \mathrm{O}_{23}$ & ginsenoside Rs2 \\
\hline 35 & 6.12 & $1147.6347[\mathrm{M}+\mathrm{H}]^{+}$ & 1147.6264 & 7.2 & $\mathrm{C}_{57} \mathrm{H}_{94} \mathrm{O}_{23}$ & ginsenoside Ra7 \\
\hline 36 & 6.28 & $917.5440[\mathrm{M}+\mathrm{H}]^{+}$ & 917.5474 & -3.7 & $\mathrm{C}_{47} \mathrm{H}_{80} \mathrm{O}_{17}$ & notoginsenoside $\mathrm{Fe}$ \\
\hline 37 & 6.36 & $1147.6348[\mathrm{M}+\mathrm{H}]^{+}$ & 1147.6264 & 7.3 & $\mathrm{C}_{57} \mathrm{H}_{94} \mathrm{O}_{23}$ & ginsenoside Ra8 \\
\hline
\end{tabular}

\subsection{PCA Analysis}

Due to the similar components contained in each sample, the differences between LX-L and LX-P were hard to identify only from the BPI chromatograms (shown in Figure 1). In this case, MVA was commonly applied to process the data, and we can clearly see the difference between LX-L and LX-P from the PCA score plot.

A two-component PCA score plot of UPLC-QTOF-MS data was utilized to depict general variation of components among the mountain cultivated ginseng samples (Figure 2). The PCA scores plot in Figure 2 can be readily divided into two big clusters. The LX-L and LX-P samples were clearly separated by the principal component 1 (PC1). Figure 3 shows the hierarchical cluster analysis (HCA) dendrogram of mountain cultivated ginseng samples. It appears that the components of them are indeed differential.

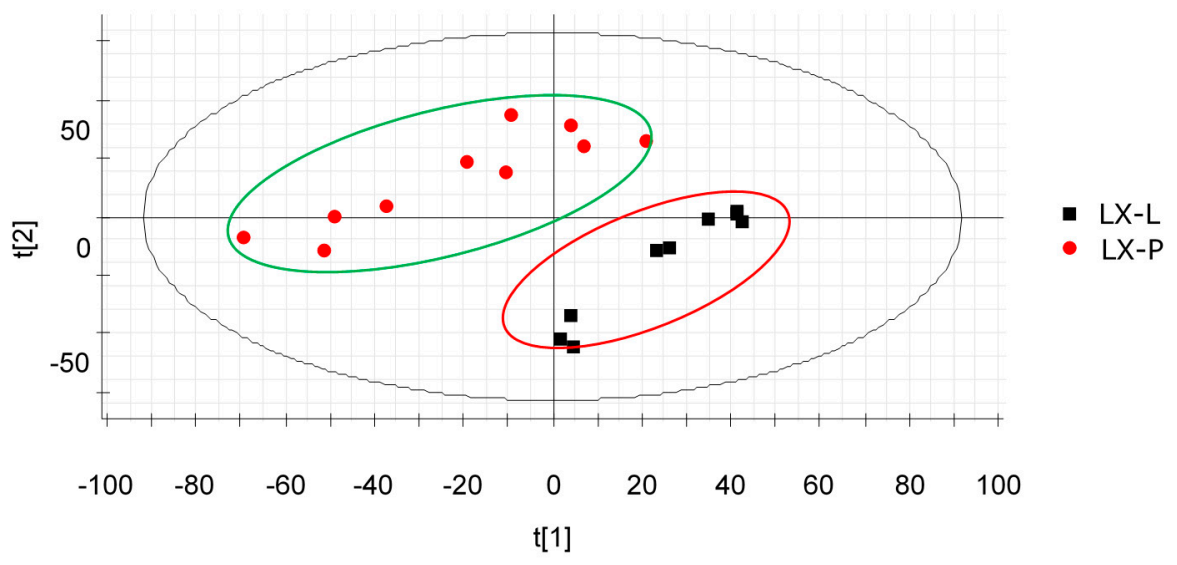

Figure 2. The principal component analysis (PCA) of LX-L and LX-P. LX-P: Natural air dried mountain cultivated ginseng; LX-L: Vacuum freeze-dried mountain cultivated ginseng. 


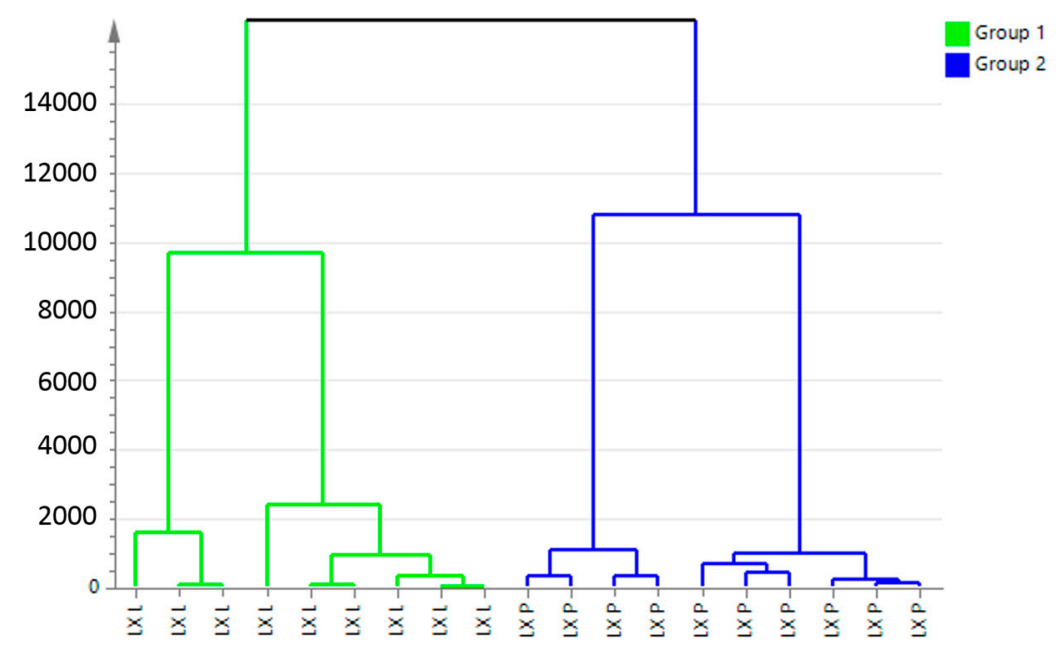

Figure 3. Hierarchical cluster analysis (HCA) dendrogram of LX-L and LX-P. LX-P: Natural air dried mountain cultivated ginseng; LX-L: Vacuum freeze-dried mountain cultivated ginseng.

\subsection{Marker Ions Analysis}

It is evident from Figure 2 that the samples were clearly clustered into two groups: one is LX-L, the other is LX-P, confirming that the components of LX-L and LX-P were indeed different in level and occurrence.

To explore the potential chemical markers that contributed most to the differences between LX-L and LX-P, UPLC-QTOF-MS/MS data were processed by supervised OPLS-DA. In the S-plot (Figure 4), each point of an exact mass retention time (EMRT) pair could be the potential markers. The $X$-axis and the $Y$-axis show the variable contributions and sample correlations, respectively. Therefore, the further away a data point is from the 0 value, the more it contributes to sample variance and the better its correlation from injection to injection. As shown in the S-plot in Figure 4, the first five ions, 1 ion ( $t_{R} 4.56 \mathrm{~min}, m / z$ 1109.6176), 2 ion ( $t_{R} 4.76 \mathrm{~min}, m / z$ 1079.6058), 3 ion ( $t_{R} 4.98 \mathrm{~min}, m / z$ 1079.6069), 4 ion ( $t_{R} 5.56 \mathrm{~min}, m / z$ 947.5623) and 5 ion ( $t_{R} 10.00 \mathrm{~min}, m / z$ 219.1749) at the lower left of the "S" were the ions from LX-P that contributed most to the differences between LX-L and LX-P. Analogously, the first nine ions, 6 ion ( $t_{R} 2.98 \mathrm{~min}, m / z$ 1033.5633), 7 ion ( $t_{R} 4.65 \mathrm{~min}, m / z$ 1195.6194), 8 ion $\left(t_{R} 4.85 \mathrm{~min}\right.$, $m / z 1165.6094) 9$ ion $\left(t_{R} 4.91 \mathrm{~min}, m / z 1195.6187\right), 10$ ion $\left(t_{R} 5.10 \mathrm{~min}, m / z 1165.6088\right), 11$ ion $\left(t_{R} 5.37 \mathrm{~min}\right.$, $m / z$ 1165.6067), 12 ion ( $t_{R} 5.93 \mathrm{~min}, m / z$ 1033.5693), 13 ion ( $t_{R} 5.95 \mathrm{~min}, m / z$ 947.5623) and 14 ion $\left(\mathrm{t}_{\mathrm{R}} 6.28 \mathrm{~min}, \mathrm{~m} / z\right.$ 917.5517) in the top right corner of the " $\mathrm{S}$ " were ions from LX-L that contributed most to the difference between LX-L and LX-P. These ions could be used as potential chemical markers to distinguish LX-L from LX-P.

Moreover, we can further confirm these spectral variables using the ion intensity plot (Figure 5) which was generated by Marker Lynx software. It was the convenient instrument to aid the profiling of marker ions. The marker $t_{R} 10.00 \mathrm{~min}, \mathrm{~m} / z 219.1748$ (Figure 5A) was from the LX-P sample and the marker ion $\mathrm{t}_{\mathrm{R}} 4.85 \mathrm{~min}, m / z 1165.6094$ (Figure $5 \mathrm{~B}$ ) was from the $\mathrm{LX}-\mathrm{L}$ sample. The representative ion intensity plot illustrated the abundance of marker ions $t_{R} 10.00 \mathrm{~min}, m / z 219.1748$ and $t_{R} 4.85 \mathrm{~min}$, $m / z 1165.6094$ over 19 MCG samples. The ions fulfilled the criteria of marker ions because they were found to have significant difference in the content levels of the samples. 


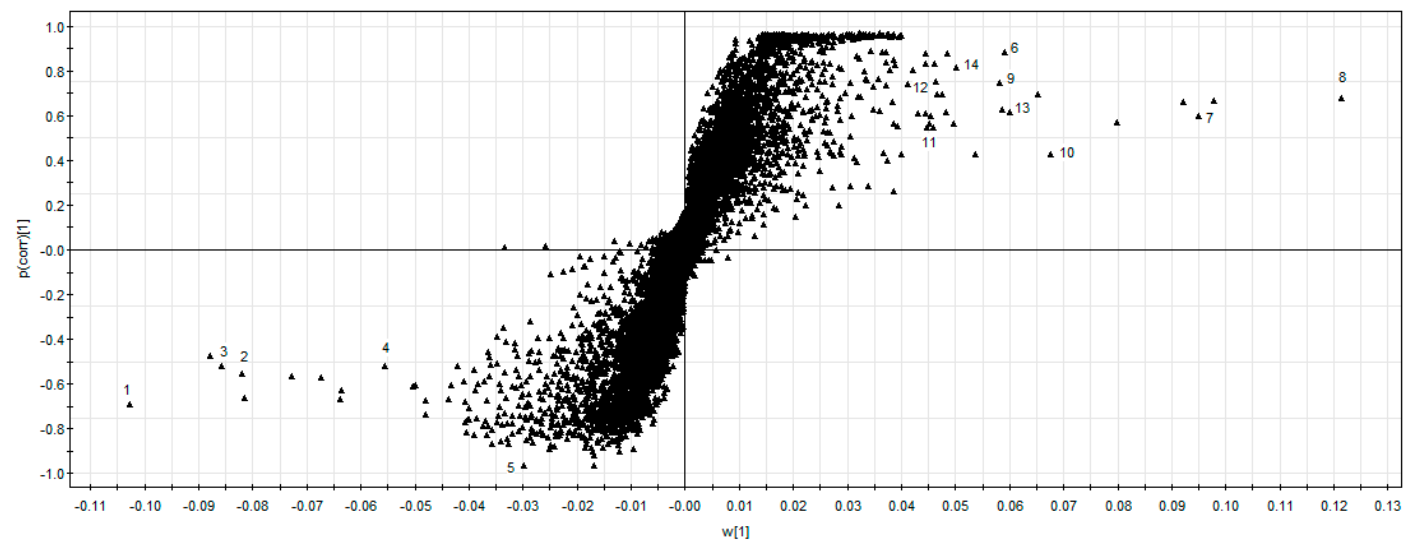

Figure 4. The S-Plot of LX-P and LX-L. 1 ion ( $t_{R} 4.56 \mathrm{~min}, m / z$ 1109.6176), 2 ion $\left(t_{R} 4.76 \mathrm{~min}\right.$, $m / z$ 1079.6058), 3 ion $\left(t_{R} 4.98 \mathrm{~min}, m / z\right.$ 1079.6069), 4 ion $\left(t_{R} 5.56 \mathrm{~min}, m / z\right.$ 947.5623) and 5 ion $\left(t_{R} 10.00 \mathrm{~min}, m / z\right.$ 219.1749); 6 ion ( $t_{R} 2.98 \mathrm{~min}, m / z$ 1033.5633), 7 ion $\left(t_{R} 4.65 \mathrm{~min}, m / z 1195.6194\right), 8$ ion ( $\left.t_{R} 4.85 \mathrm{~min}, m / z 1165.6094\right) 9$ ion ( $\left.t_{R} 4.91 \mathrm{~min}, m / z 1195.6187\right), 10$ ion ( $\left.t_{R} 5.10 \mathrm{~min}, m / z 1165.6088\right)$, 11 ion ( $t_{\mathrm{R}} 5.37 \mathrm{~min}, \mathrm{~m} / z$ 1165.6067), 12 ion ( $\mathrm{t}_{\mathrm{R}} 5.93 \mathrm{~min}, \mathrm{~m} / z$ 1033.5693), 13 ion ( $\mathrm{t}_{\mathrm{R}} 5.95 \mathrm{~min}, \mathrm{~m} / z$ 947.5623) and 14 ion $\left(\mathrm{t}_{\mathrm{R}} 6.28 \mathrm{~min}, \mathrm{~m} / \mathrm{z}\right.$ 917.5517).
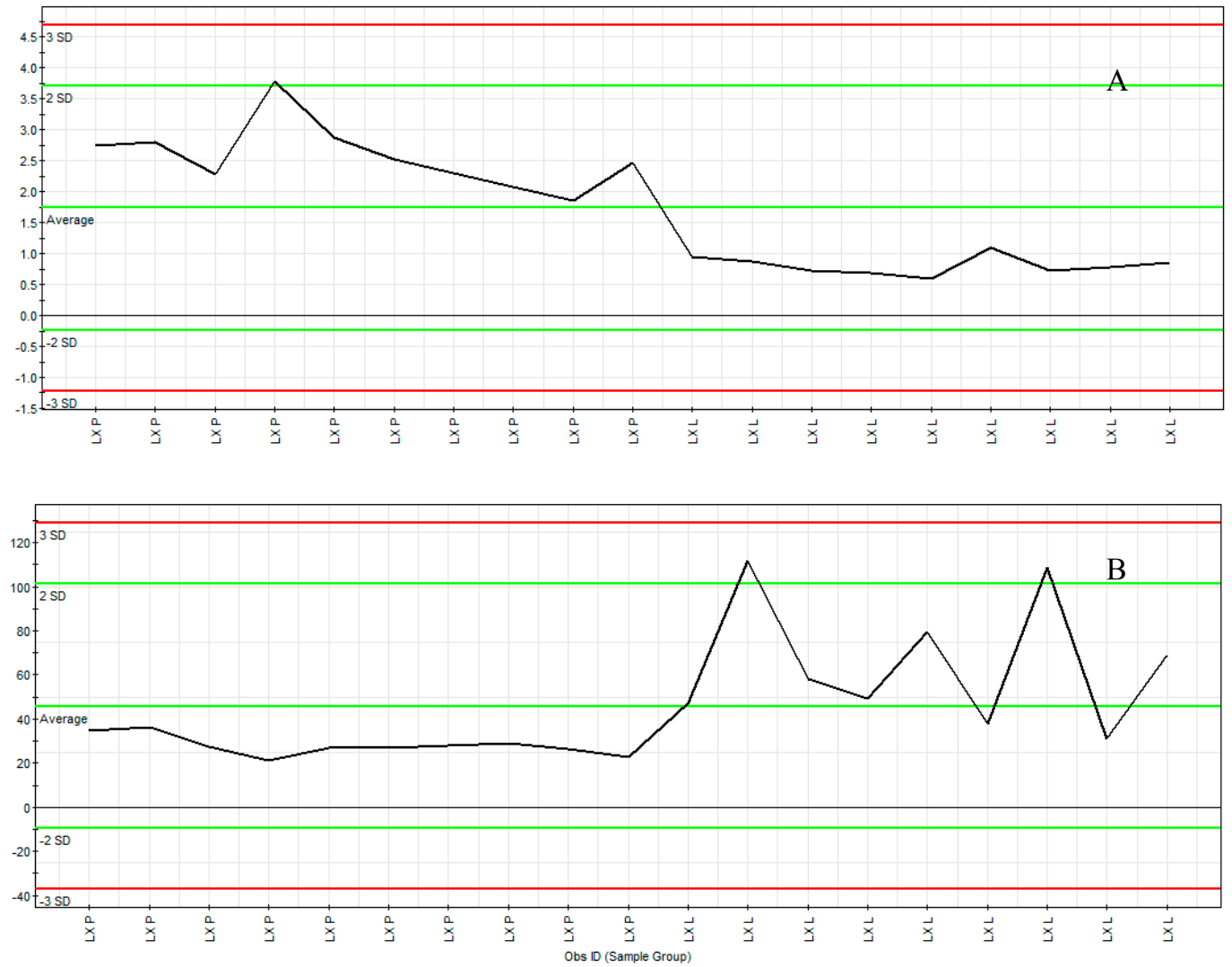

Figure 5. The ion intensity plot of LX-P and LX-L. LX-P: Natural air dried mountain cultivated ginseng; LX-L: Vacuum freeze-dried mountain cultivated ginseng; (A) Dendrolasin at $m / z 219.1748$ $\left(\mathrm{t}_{\mathrm{R}} 10.00 \mathrm{~min}\right)$; (B) Mal-ginsenoside Rc at $\mathrm{m} / z 1165.6094$ ( $\left.\mathrm{t}_{\mathrm{R}} 4.85 \mathrm{~min}\right)$.

\subsection{Maker Ions Assignment}

Once having obtained the potential markers, element composition calculation was performed for the target markers. The molecular formula of the markers can be easily obtained by calculating their 
accurate masses. The next step was to search against a database and use the retention times as correlation references to identify the markers. Finally, the structure of the markers was confirmed by the fragments which appeared in the high capillary electrophoresis (CE) scan. The results are in Table 2.

Table 2. Identified maker ions of mountain cultivated ginseng (MCG) in different drying methods.

\begin{tabular}{|c|c|c|c|c|c|c|c|c|c|}
\hline No. & Identification & $\underset{(\min )}{t_{R}}$ & $\begin{array}{l}\text { Molecular } \\
\text { Formula }\end{array}$ & Ion & $\begin{array}{c}\text { Mean Measured } \\
\text { Mass }\end{array}$ & $\begin{array}{l}\text { Theoretical } \\
\text { Exact Mass }\end{array}$ & $\begin{array}{c}\text { Mass } \\
\text { Accuracy } \\
\text { (ppm) }\end{array}$ & $\begin{array}{l}\text { Fragment } \\
\text { Ions }\end{array}$ & Classification \\
\hline 1 & ginsenoside Rb1 & 4.56 & $\mathrm{C}_{54} \mathrm{H}_{92} \mathrm{O}_{23}$ & {$[\mathrm{M}+\mathrm{H}]^{+}$} & 1109.6176 & 1109.6180 & -0.4 & $\begin{array}{l}929,767,605, \\
425\end{array}$ & LX-P \\
\hline 2 & ginsenosede Rc & 4.76 & $\mathrm{C}_{53} \mathrm{H}_{90} \mathrm{O}_{22}$ & {$[\mathrm{M}+\mathrm{H}]^{+}$} & 1079.6058 & 1079.6002 & 5.1 & $929,767,605$ & LX-P \\
\hline 3 & ginsenoside $\mathrm{Rb} 2$ & 4.98 & $\mathrm{C}_{53} \mathrm{H}_{90} \mathrm{O}_{22}$ & {$[\mathrm{M}+\mathrm{H}]^{+}$} & 1079.6069 & 1079.6002 & 6.2 & $929,767,605$ & LX-P \\
\hline $\begin{array}{l}4 \\
5\end{array}$ & $\begin{array}{l}\text { ginsenoside Rg6 } \\
\text { dendrolasin }\end{array}$ & $\begin{array}{l}5.56 \\
10.00\end{array}$ & $\begin{array}{l}\mathrm{C}_{56} \mathrm{H}_{94} \mathrm{O}_{24} \\
\mathrm{C}_{15} \mathrm{H}_{22} \mathrm{O}\end{array}$ & $\begin{array}{l}{[\mathrm{M}+\mathrm{H}]^{+}} \\
{[\mathrm{M}+\mathrm{H}]^{+}}\end{array}$ & $\begin{array}{l}767.4960 \\
219.1748\end{array}$ & $\begin{array}{l}767.4946 \\
219.1749\end{array}$ & $\begin{array}{c}1.8 \\
-0.5\end{array}$ & $\begin{array}{c}425 \\
621,459 \\
203,149\end{array}$ & $\begin{array}{l}\text { LX-P } \\
\text { LX-P }\end{array}$ \\
\hline 6 & mal-ginsenoside Re & 2.98 & $\mathrm{C}_{51} \mathrm{H}_{84} \mathrm{O}_{21}$ & {$[\mathrm{M}+\mathrm{H}]^{+}$} & 1033.5633 & 1033.5583 & 4.8 & $\begin{array}{l}1015,853 \\
767,605\end{array}$ & LX-L \\
\hline 7 & mal-ginsenoside $\mathrm{Rb} 1$ & 4.65 & $\mathrm{C}_{57} \mathrm{H}_{94} \mathrm{O}_{26}$ & {$[\mathrm{M}+\mathrm{H}]^{+}$} & 1195.6194 & 1195.6112 & 6.8 & $\begin{array}{c}1109,1015 \\
853,835,785 \\
605,425\end{array}$ & LX-L \\
\hline 8 & mal-ginsenoside Rc & 4.85 & $\mathrm{C}_{56} \mathrm{H}_{92} \mathrm{O}_{25}$ & {$[\mathrm{M}+\mathrm{H}]^{+}$} & 1165.6094 & 1165.6006 & 7.5 & $\begin{array}{c}1187,1079 \\
1015,853 \\
835,605,425 \\
411\end{array}$ & LX-L \\
\hline 9 & $\begin{array}{c}\text { mal-ginsenoside Rb1 } \\
\text { isomer }\end{array}$ & 4.91 & $\mathrm{C}_{57} \mathrm{H}_{94} \mathrm{O}_{26}$ & {$[\mathrm{M}+\mathrm{H}]^{+}$} & 1195.6187 & 1195.6112 & 6.2 & $\begin{array}{c}1109,1015 \\
853,785\end{array}$ & LX-L \\
\hline 10 & mal-ginsenoside $\mathrm{Rb} 2$ & 5.10 & $\mathrm{C}_{56} \mathrm{H}_{92} \mathrm{O}_{25}$ & {$[\mathrm{M}+\mathrm{H}]^{+}$} & 1165.6088 & 1165.6006 & 7.0 & $\begin{array}{l}1079,871 \\
853,411\end{array}$ & LX-L \\
\hline 11 & mal-ginsenoside Rb3 & 5.37 & $\mathrm{C}_{56} \mathrm{H}_{92} \mathrm{O}_{25}$ & {$[\mathrm{M}+\mathrm{H}]^{+}$} & 1165.6067 & 1165.6006 & 5.2 & $\begin{array}{c}1079,871 \\
853,411\end{array}$ & LX-L \\
\hline 12 & $\begin{array}{l}\text { mal-ginsenoside Rd } \\
\text { iosmer }\end{array}$ & 5.93 & $\mathrm{C}_{51} \mathrm{H}_{84} \mathrm{O}_{21}$ & {$[\mathrm{M}+\mathrm{H}]^{+}$} & 1033.5653 & 1033.5583 & 6.7 & $\begin{array}{c}947,871,785 \\
605\end{array}$ & LX-L \\
\hline 13 & gypenoside XVII & 5.95 & $\mathrm{C}_{48} \mathrm{H}_{82} \mathrm{O}_{18}$ & {$[\mathrm{M}+\mathrm{H}]^{+}$} & 947.5623 & 947.5579 & 4.6 & $\begin{array}{c}785,767,605 \\
443\end{array}$ & LX-L \\
\hline 14 & notoginsenoside Fe & 6.28 & $\mathrm{C}_{47} \mathrm{H}_{80} \mathrm{O}_{17}$ & {$[\mathrm{M}+\mathrm{H}]^{+}$} & 917.5517 & 917.5474 & -3.7 & $\begin{array}{c}899,785,737 \\
605\end{array}$ & LX-L \\
\hline
\end{tabular}

mal: malonyl; LX-P: Natural air dried mountain cultivated ginseng; LX-L: Vacuum freeze-dried mountain cultivated ginseng.

By matching the retention time and accurate mass with the published known compounds, ion 1 ( $t_{R} 4.56 \mathrm{~min}, m / z$ 1109.6176), ion $2\left(t_{R} 4.76 \mathrm{~min}, m / z\right.$ 1079.6058), $3\left(t_{R} 4.98 \mathrm{~min}, m / z\right.$ 1079.6069), ion $4\left(t_{R} 5.56 \mathrm{~min}, m / z\right.$ 947.5623), and ion $5\left(t_{R} 10.00 \mathrm{~min}, m / z\right.$ 219.1749) in the LX-P samples were identified as ginsenoside $\mathrm{Rb} 1$, ginsenoside $\mathrm{Rc}$, ginsenoside $\mathrm{Rb} 2$, ginsenoside $\mathrm{Rg} 6$, and dendrolasin, respectively. Similarly, ion $6\left(t_{R} 2.98 \mathrm{~min}, m / z\right.$ 1033.5633), ion 7 ( $t_{R} 4.65 \mathrm{~min}, \mathrm{~m} / z$ 1195.6194), ion 8 ( $t_{R} 4.85 \mathrm{~min}, m / z$ 1165.6094), ion 9 ( $t_{R} 4.91 \mathrm{~min}, m / z$ 1195.6187), ion $10\left(t_{R} 5.10 \mathrm{~min}, m / z\right.$ 1165.6088), ion $11\left(t_{R} 5.37 \mathrm{~min}, m / z 1165.6067\right)$, ion $12\left(t_{R} 5.93 \mathrm{~min}, \mathrm{~m} / z\right.$ 1033.5693), ion $13\left(t_{R} 5.95 \mathrm{~min}\right.$, $m / z$ 947.5623), and ion $14\left(t_{R} 6.28 \mathrm{~min}, \mathrm{~m} / z\right.$ 917.5517) in the LX-L samples were affirmed to be malonyl-ginsenoside Re, malonyl-ginsenoside Rb1, malonyl-ginsenoside Rc, malonyl-ginsenoside $\mathrm{Rb} 1$ isomer, malonyl-ginsenoside $\mathrm{Rb} 2$, malonyl-ginsenoside $\mathrm{Rb} 3$, malonyl-ginsenoside $\mathrm{Rd}$ isomer, gypenoside XVII, and notoginsenoside Fe, respectively.

After assigning the maker ions, we could easily find that mountain cultivated ginseng processed in different drying methods have a significant different in their chemical components. Malonyl-ginsenosides, which are naturally present in ginseng, were abundant in LX-L. However, LX-P contained a large number of major ginsenosides which were derived from malonyl-ginsenosides by natural air drying. This study indicated that the drying method is an essential factor to controlling the quality of mountain cultivated ginseng, and the vacuum freeze-drying method was found to improve the content of malonyl-ginsensides in mountain cultivated ginseng.

\section{Materials and Methods}

\subsection{Ginseng Samples and Sample Processing}

There were 19 MCG samples which were cultivated for 15 years before being collected from Ji'an city of the Jilin province of China. All these samples were fresh ginseng, which were then processed by natural air drying or by vacuum freeze-drying, respectively. All of these processed samples were identified by Professor Xiangri Li (School of Chinese Materia Medica, Beijing University of Chinese 
Medicine) and deposited in the specimen cabinet of traditional Chinese medicine of Beijing University of Chinese Medicine.

\subsection{Sample Preparation}

The dried roots were powdered to a homogeneous size, and sieved through a No. 65 mesh. The amount of $0.4 \mathrm{~g}$ of ginseng powder was accurately weighed and then placed in a triangular flask with $50 \mathrm{~mL}$ methanol, filled with a plug, weighed, and ultrasonic-extracted for $30 \mathrm{~min}$. After cooling to room temperature, the loss of weight was replenished with methanol and then the sample was filtrated. Precision draw subsequent filtrate $25 \mathrm{~mL}$ and concentrated it into residue, which was then dissolved in methanol in a 10-mL volumetric flask. Finally, the extraction solution was injected into the UPLC system after being filtered through a $0.22-\mu \mathrm{m}$ filter membrane.

\subsection{Reagents}

Fisher Optima grade acetonitrile, methanol, and isopropanol were purchased from Thermo Fisher Co. (Waltham, MA, USA). Formic acid and leucine enkephaline were purchased from Sigma Aldrich (St. Louis, MI, USA). Ultra-pure water was obtained in our laboratory via a Milli-Q water purification system (Millipore Corporation, Bedford, MA, USA). Ginsenoside Rg1, Re, Rb1, Rf, Rb2 and $\mathrm{Rb} 3$ standards were purchased from the National Institute for the Pharmaceutical and Biological Products (Beijing, China). Ginsenoside Rc, Rg2 standards were obtained from the Beijing Xiantong era Pharmaceutical Co. Ltd. (Beijing, China). The standards were dissolved in methanol and stored at $4{ }^{\circ} \mathrm{C}$ until analysis.

\subsection{UPLC-Q-TOF Conditions}

\subsubsection{Liquid Chromatography Conditions}

UPLC separation was performed by an ACQUITY UPLC system (Waters Corporation, Milford, Massachusetts) with an ACQUITY UPLC BEH C 18 column $(100 \mathrm{~mm} \times 2.1 \mathrm{~mm}, 1.7 \mu \mathrm{m})$. The column temperature was controlled at $40{ }^{\circ} \mathrm{C}$. The flow rate was kept at $400 \mu \mathrm{L} / \mathrm{min}$. The binary gradient elution solvent consisted of water with $0.1 \%$ formic acid (A) and acetonitrile (B). The UPLC elution conditions were optimized as follows: initially, $A: B=81: 19 ; 0-7 \mathrm{~min}, \mathrm{~A}: \mathrm{B}=50: 50 ; 7-12 \mathrm{~min}, \mathrm{~A}: \mathrm{B}=4: 96$; 12-13 min, $\mathrm{A}: \mathrm{B}=2: 98 ; 13-25 \mathrm{~min}, \mathrm{~A}: \mathrm{B}=2: 98 ; 25-26 \mathrm{~min}, \mathrm{~A}: \mathrm{B}=81: 19 ; 26-29 \mathrm{~min}, \mathrm{~A}: \mathrm{B}=81: 19$. The total run time was $29 \mathrm{~min}$, and the sample injection volume was $2 \mu \mathrm{L}$.

\subsubsection{Mass Spectrometry Conditions}

MS detection was performed on a quadrupole orthogonal acceleration time-of-flight tandem mass spectrometer (Waters Synapt MS System). The data acquisition mode was $\mathrm{MS}^{\mathrm{E}}$ and the ion polarity was set to positive mode $\left(\mathrm{ESI}^{+}\right)$. The optimized condition was desolvation gas at $480.0 \mathrm{~L} / \mathrm{h}$ at a temperature of $350{ }^{\circ} \mathrm{C}$, cone gas at $50 \mathrm{~L} / \mathrm{h}$ and source temperature at $120^{\circ} \mathrm{C}$, capillary and cone voltage at $3.0 \mathrm{kV}$ and $20 \mathrm{~V}$, respectively. The lock mass compound used was leucine enkephaline. The low-energy scan collision energy was set at $5 \mathrm{eV}$ in order to collect information on the intact precursor ions, and high-energy scan energy was set at $20 \mathrm{eV}-30 \mathrm{eV}$ to obtain the fragment ions. The UPLC-MS data acquisition was controlled by Mass Lynx 4.1 Mass Spectrometry Software (Waters Corporation).

\subsection{Data Processing Procedure}

For post-acquisition data processing, the MVA such as PCA and OPLS-DA were performed by Marker Lynx XS, which is an application manager for Mass Lynx software. The structural elucidation was performed by the Mass Fragment tool provided by Mass Lynx. 


\subsubsection{The PCA Scores Plot of Samples}

From the chromatographic trace, we actually acquired three-dimensional (3-D) data which represented retention time, $m / z$, and intensity. It was necessary to convert each data point into a 2-D matrix, i.e., an exact mass retention time (EMRT) pair. After the EMRT 2-D matrix was obtained, the MVA interface was launched with all EMRT information automatically imported so that the extended statistics module PCA could be executed.

\subsubsection{The Scatter Plot (S-Plot) from OPLS-DA Analysis}

The loading plot (S-plot) of every group pair was processed by OPLS-DA analysis. In the S-plot, the leading contributing EMRT pairs could be captured selectively so that a list of top contributing markers from each sample group was generated and saved as a text file.

\subsubsection{The Elemental Composition Calculation for the Targeting Markers}

The matched elemental composition of markers was obtained by calculating the exact mass. Then, we searched against an existing database to acquire the chemical structure. Once the identity of a marker was tentatively identified, its fragment ions could be easily obtained by going back to the raw data file to investigate the high capillary electrophoresis (CE) scan of the samples. The fragment ions which we obtained through the Mass Fragment tool of Mass Lynx was used for elucidating the structure.

\section{Conclusions}

The multivariate statistical analysis (MAV) and UPLC-QTOF-MS/MS were combined to analyze mountain cultivated ginseng subjected to either natural air drying or vacuum freeze-drying. The combination of the high-resolution UPLC separation and high-resolution MS detection along with the multivariate statistical analysis (MAV) details of the samples proved able to identify and select the important marker ions in both samples, even at low concentration levels. As a result, this is the first time that the differences between LX-P and LX-L have been observed systematically at the level of their chemical components.

Acknowledgments: This study was supported by grants from National Natural Science Foundation of China (no. 81073041) and the Specialized Research Fund for the Doctoral Program of Higher Education of China (no. 20100013120010).

Author Contributions: Xin-fang $X u$, Rui-chao Lin, and Xiang-ri Li conceived and designed the study. Xin-fang $X u$, Shu-ya Xu, Ying Zhang, Hui Zhang, and Meng-nan Liu collected the samples and performed the experiments. Xin-fang Xu and Xiang-ri Li wrote the paper. Huan Liu, Yan Gao, Xue Xue, and Hui Xiong reviewed and edited the manuscript. All authors read and approved the manuscript.

Conflicts of Interest: The authors declare that there is no conflict of interests regarding the publication of this paper.

\section{References}

1. Hou, G.; Niu, J.; Song, F.; Liu, Z.; Liu, S. Studies on the interactions between ginsenosides and liposome by equilibrium dialysis combined with ultrahigh performance liquid chromatography-tandem mass spectrometry. J. Chromatogr. B 2013, 923-924, 1-7. [CrossRef] [PubMed]

2. Wang, Q.; Sun, L.H.; Jia, W.; Liu, X.M.; Dang, H.X.; Mai, W.L.; Ning, W.; Steinmetz, A.; Wang, Y.Q.; Xu, C.J. Comparison of ginsenosides $\mathrm{Rg} 1$ and $\mathrm{Rb} 1$ for their effects on improving scopolamine-induced learning and memory impairment in mice. Phytother. Res. 2010, 24, 1748-1754. [CrossRef] [PubMed]

3. Schram, G.; Zhang, L.; Derakhchan, K.; Ehrlich, J.R.; Belardinelli, L.; Nattel, S. Ranolazine: Ion-channel-blocking actions and in vivo electrophysiological effects. Br. J. Pharmacol. 2004, 142, 1300-1308. [CrossRef] [PubMed]

4. Cheng, Y.; Shen, L.H.; Zhang, J.T. Anti-amnestic and anti-aging effects of ginsenoside Rgl and Rbl and its mechanism of action. Acta Pharmacol. Sin. 2005, 26, 143-149. [CrossRef] [PubMed]

5. Ramesh, T.; Kim, S.W.; Hwang, S.Y.; Sohn, S.H.; Yoo, S.K.; Kim, S.K. Panax ginseng reduces oxidative stress and restores antioxidant capacity in aged rats. Nut. Res. 2012, 32, 718-726. [CrossRef] [PubMed] 
6. Yamabe, N.; Kim, Y.J.; Lee, S.; Cho, E.J.; Park, S.H.; Ham, J.; Kim, H.Y.; Kang, K.S. Increase in antioxidant and anticancer effects of ginsenoside Re-lysine mixture by Maillard reaction. Food Chem. 2013, 138, 876-883. [CrossRef] [PubMed]

7. Lee, J.S.; Hwang, H.S.; Ko, E.J.; Lee, Y.N.; Kwon, Y.M.; Kim, M.C.; Kang, S.M. Immunomodulatory activity of red ginseng against influenza A virus infection. Nutrients 2014, 6, 517-529. [CrossRef] [PubMed]

8. Kwon, K.R.; Park, W.P.; Kang, W.M.; Jeon, E.Y.; Jang, J.H. Identification and Analysis of Differentially Expressed Genes in Mountain Cultivated Ginseng and Mountain Wild Ginseng. J. Acupunct. Meridian Stud. 2011, 4, 123-128. [CrossRef]

9. Liu, D.; Li, Y.-G.; Xu, H.; Sun, S.-Q.; Wang, Z.-T. Differentiation of the root of Cultivated Ginseng, Mountain Cultivated Ginseng and Mountain Wild Ginseng using FT-IR and two-dimensional correlation IR spectroscopy. J. Mol. Struct. 2008, 883-884, 228-235. [CrossRef]

10. Committee, C.P. Pharmacopeia of People's Republic of China; Chinese Medicine Science and Technology: Beijing, China, 2005.

11. Hwang, J.W.; Oh, J.H.; Yoo, H.S.; Lee, Y.W.; Cho, C.K.; Kwon, K.R.; Yoon, J.H.; Park, J.; Her, S.; Lee, Z.W. Mountain ginseng extract exhibits anti-lung cancer activity by inhibiting the nuclear translocation of NF- $\mathrm{KB}$. Am. J. Chin. Med. 2012, 40, 187-202. [CrossRef] [PubMed]

12. Ren, G.; Chen, F. Determination of moisture content of ginseng by near infra-red reflectance spectroscopy. Food Chem. 1997, 60, 433-436. [CrossRef]

13. Davidson, V.J.; Martynenko, A.I.; Parhar, N.K.; Sidahmed, M.; Brown, R.B. Forced-Air Drying of Ginseng Root: Pilot-Scale Control System for Three-Stage Process. Dry. Technol. 2009, 27, 451-458. [CrossRef]

14. Liu, X.; Qiu, Z.; Wang, L.; Chen, Y. Quality evaluation of Panax notoginseng extract dried by different drying methods. Food Bioprod. Process. 2011, 89, 10-14. [CrossRef]

15. Ren, G.; Feng, C. Drying of American ginseng (Panax quinquefolium roots by microwave-hot air combination. J. Food Eng. 1998, 35, 433-443. [CrossRef]

16. Popovich, D.G.; Hu, C.; Durance, T.D.; Kitts, D.D. Retention of Ginsenosides in Dried Ginseng Root: Comparison of Drying Methods. J. Food Sci. 2006, 70, s355-s358. [CrossRef]

17. Ning, X.; Lee, J.; Han, C. Drying characteristics and quality of red ginseng using far-infrared rays. J. Ginseng Res. 2015, 39, 371-375. [CrossRef] [PubMed]

18. Kasper, J.C.; Winter, G.; Friess, W. Recent advances and further challenges in lyophilization. Eur. J. Pharm. Biopharm. 2013, 85, 162-169. [CrossRef] [PubMed]

19. Sarraguça, M.C.; Beer, T.D.; Vervaet, C.; Remon, J.P.; Lopes, J.A. A batch modelling approach to monitor a freeze-drying process using in-line Raman spectroscopy. Talanta 2010, 83, 130-138.

20. Fang, L.I.; Qiao, L.I.; Song, D.; Liu, P.P.; Chong-Ning, L.V.; Wang, J.; Jia, L.Y.; Jin-Cai, L.U. Effect of different drying methods on ginsenosides in flower of Panax ginseng and Panax quinquefolius. Chin. Tradit. Herb. Dru. 2015, 46, 2937-2942.

21. Wang, Y.; Huang, M.; Sun, R.; Lei, P. Extraction, characterization of a Ginseng fruits polysaccharide and its immune modulating activities in rats with Lewis lung carcinoma. Carbohydr. Polym. 2015, 127, 215-221. [CrossRef] [PubMed]

22. Jin, Y.; Kim, Y.J.; Jeon, J.N.; Wang, C.; Min, J.W.; Noh, H.Y.; Yang, D.C. Effect of White, Red and Black Ginseng on Physicochemical Properties and Ginsenosides. Plant Foods Hum. Nutr. 2015, 70, 141-145. [CrossRef] [PubMed]

23. Chen, J.; Du, B.; Cai, W.; Xu, B. Ginsenosides and amino acids in flavored ginseng chips as affected byfood formulation and processing technology. LWT Food Sci. Technol. 2015, 62, 517-524. [CrossRef]

24. Qiu, Y.; Lu, X.; Pang, T.; Ma, C.; Li, X.; Xu, G. Determination of radix ginseng volatile oils at different ages by comprehensive two-dimensional gas chromatography/time-of-flight mass spectrometry. J. Sep. Sci. 2008, 31, 3451-3457. [CrossRef] [PubMed]

Sample Availability: Samples of the 41 compounds are available from the authors. 